\title{
Chrétien de Troyes, Cligès
}

\section{Maria Colombo Timelli}

\section{(2) OpenEdition}

\section{Journals}

\section{Édition électronique}

URL : https://journals.openedition.org/studifrancesi/25937

DOI : 10.4000/studifrancesi.25937

ISSN : 2427-5856

\section{Éditeur}

Rosenberg \& Sellier

\section{Édition imprimée}

Date de publication : 1 avril 2007

Pagination : 146-147

ISSN : 0039-2944

\section{Référence électronique}

Maria Colombo Timelli, «Chrétien de Troyes, Cligès », Studi Francesi [En ligne], 151 (LI | I) | 2007, mis en ligne le 30 novembre 2015, consulté le 23 novembre 2021. URL : http://journals.openedition.org/ studifrancesi/25937 ; DOI : https://doi.org/10.4000/studifrancesi.25937

\section{Ce document a été généré automatiquement le 23 novembre 2021.}

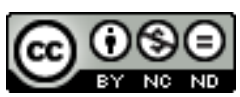

Studi Francesi è distribuita con Licenza Creative Commons Attribuzione - Non commerciale - Non opere derivate 4.0 Internazionale. 


\title{
Chrétien de Troyes, Cligès
}

\author{
Maria Colombo Timelli
}

\section{RÉFÉRENCE}

CHRÉTIEN DE TROYES, Cligès, Édition bilingue. Publication, traduction, présentation et notes par Laurence HARF-LANCNER, Paris, Champion («Champion Classiques Moyen Age», 16), 2006, pp. 463.

1 Laurence Harf-Lancner enrichit la collection bilingue de Champion par une nouvelle édition de Cligés, basée sur la copie de Guiot, accompagnée d'une traduction en français moderne en prose.

2 L'introduction définit d'abord le deuxième roman de Chrétien par ce qu'il n'est pas: ni roman d'antiquité, ni roman arthurien, ni roman tristanien, ni roman oriental, il réunit cependant des éléments de toutes ces 'catégories'. Laurence Harf ne renonce cependant pas à présenter ce roman relativement inclassable à travers ses traits marquants: quelques traces de l'actualité des années 1170-1176, une géographie réaliste, et, sur le plan structurel, le rôle du prologue et la nette bipartition du récit. Autre question fondamentale, qui a occupé la critique pendant tout le $\mathrm{xx}^{\mathrm{e}}$ siècle et qui est loin d'avoir trouvé une réponse définitive, le rapport Tristan-Cligés: l'éditrice propose ici de lire le roman de Chrétien, plutôt que comme un 'anti-Tristan', comme un 'simili-Tristan', et rappelle, à côté des rapprochements explicites, les nombreux effets d'échos d'un roman à l'autre. Elle ajoute encore une réflexion sur le 'travail de marqueterie' réalisé par le poète champenois à partir de la matière littéraire de son temps (reprise de thèmes et de ressources rhétoriques) et analyse le rôle joué par les deux adjuvants, Jean et Thessala, véritables 'meneurs du jeu' dans l'histoire du couple Cligés-Fenice.

3 Les aspects philologiques ne sont pas négligés, avec une présentation synthétique des manuscrits et une étude de la langue de Guiot. La bibliographie mérite aussi d'être signalée, en raison de la mise à jour raisonnée qu'elle offre sur les éditions / traductions récentes (signalons que l'édition du remaniement en prose $\mathrm{du} \mathrm{Xv}^{\mathrm{e}}$ siècle par Lucien de Poortere, indiquée p. 53, est en réalité un mémoire de licence de la Faculté de 
Philosophie et Lettres, Université Catholique de Louvain, 1968), la tradition manuscrite et la pratique éditoriale, et les études spécialement consacrées au roman.

4 L'édition est dans l'ensemble fidèle au manuscrit de Guiot, dont les leçons problématiques sont corrigées sur la base surtout du ms. BnF fr. 1450 (toutes les interventions sont indiquées dans l'apparat en bas de page, alors qu'une sélection des variantes occupe les pp. 427-434); une remarque: contrairement à ce qui est dit à la $p$. 43, les 77 lettres montantes du manuscrit ne sont pas indiquées dans l'édition par une capitale en gras, mais bien par un double interligne (ainsi aux vv. 45, 235, 441 etc.); d'autre part, des divergences s'observent avec la liste de ces lettres donnée par LuttrellGregory aux pp. 319-320 de leur édition critique (Cambridge, Brewer, 1993).

5 La traduction, agréable à lire et fidèle sans excès au texte médiéval, est accompagnée de quelques notes critiques également en bas de page, mais sans renvoi aux vers correspondants; un glossaire sélectif, avec liste des occurrences, permet par ailleurs de vérifier la signification des mots n'existant plus en français moderne. Dans l'index des noms propres, seule la première occurrence est indiquée. 